\title{
The treatment of child abuse in an in-patient setting
}

\author{
Roger Kennedy, Consultant Psychotherapist, Families Unit, Cassel Hospital, \\ Richmond, Surrey
}

The Families Unit at the Cassel Hospital is the only medical establishment with in-patient beds for whole families, and it can provide the opportunity for detailed and relatively safe observation and treatment of severely disordered families. A number of different kinds of family are treated, including those in which a mother has suffered a severe post puerperal breakdown, those in which one or more members of the family have a severe psychiatric condition such as chronic depression, as well as families whose whole functioning in many aspects of life has broken down.

In addition, in the last four years, we have had increasing experience with a group of patients who normally do not respond well to treatment, and who provide professional workers with what often appear to be intractable problems. This is a group of patients who have neglected their children over a period of years and have subjected them to one or more episodes of violent attacks. We have developed particular ways of working with such families and the professionals involved with them, and the purpose of this paper is to summarise the treatment programme, with clinical examples, as well as to discuss some of the implications of our work.

I have gathered together observations from 18 physically abusing families treated as in-patients, with admissions of the whole family ranging from four weeks to 18 months, with an average stay of approximately six months; and a total to date of 97 such families seen for out-patient consultation, 53 of whom have had one or more children in care at assessment. It is our long-term aim to study the effects of abuse on the children and the effectiveness of our treatment programme, which aims to prevent further abuse, over the next five years. The first in a series of outcome studies of the treatment of inpatient adults has already been published and shows significantly successful results. ${ }^{1}$

\section{Outline of treatment programme}

A comprehensive description of the Families Unit treatment programme is already published. ${ }^{2}$ Nine to ten families are admitted at any one time for a month's assessment followed by the possibility of treatment up to 18 months. It should be emphasised that we tend to admit only those families where other kinds of treatment, including family therapy, drug treatment and intervention at school, have not succeeded. That is, we take the most seriously disturbed families, within certain limits. We do not aim to treat patients suffering from acute psychoses; nor do we accept drug addicts, severe alcoholics or major crime offenders, all of whom we have so far found unable to use our resources, or else have a very destructive effect on the patient group. In addition, we have to consider the safety of the children in the hospital.

The programme, which does not include the use of psychotropic drugs, consists of detailed nursing work focused on everyday family activities and parenting skills, combined with two to three times weekly psychotherapy for parents and, if necessary, for children. Family meetings with nurse and therapist take place regularly to integrate nursing and therapy. There is a focus both on family living skills and on individual needs and difficulties. The aim is to restore families to their communities so that they can either continue with life unaided or at least use their local resources more effectively. The combination of working with the whole family and providing a setting for detailed understanding of the individual parent and child offers the opportunity of making close observations of the nature of family breakdown. It also enables us to make a thorough assessment of a family's strengths and failings, including the risk of further abuse. It is in my experience often difficult to assess the risk without such close observation over some weeks, and for this reason we are increasingly being asked by social work agencies and other professionals for help in this way.

There are perhaps still misgivings that bringing children into a psychiatric unit would expose them to malign influences which could seriously affect and emotionally harm them. These fears are not borne out by events. Not only do we rarely have to separate children from their parents but, on the contrary, on admission many children begin to blossom when they are relieved of the burden of trying to meet their disturbed parents' emotional demands which they are not equipped to provide, or because they then receive the attention to their needs which their parents were unable to provide. Monitoring and using information about the child him or herself, as opposed to the child created by parental needs, is another advantage of in-patient treatment. Further- 
more, by expecting the father, where present, to be admitted, we aim to set great store by attempting to integrate the whole family, as so often the family's problems are caused by disturbance between couples. I should add that bread-winners are generally expected to continue their employment even when admitted.

We place great emphasis on monitoring at-risk families and making sure the children are safe. This requires both detailed attention to what is happening to the family in the Unit day by day and considerable liaison with the relevant social service agency.

Safety of the children in the hospital is maintained in a number of ways. There are various settings to see, hear about or discuss patients, such as daily meetings with patients, daily staff meetings and regular reviews and supervisions. The safety is also maintained by a network of staff relationships, from the nurse and therapist of a particular family across to the on-call duty team at night and at weekends. For the network of relationships to provide a secure 'holding' environment, there needs to be clear and effective transmission of information between the workers. In addition, each family will have its own particular focus of work and nursing plan. Thus, early in admission, an abusing family may well have fairly severe constraints on their freedom, e.g. they may not be allowed out of the hospital unaccompanied, until we feel able to trust them. If treatment proceeds successfully, the constraints will gradually be reduced and the progress of the family monitored by reviews as well as planning meetings with the relevant social work agency.

In general, there are five basic elements to treatment in the Families Unit, which I have summarised as follows:

(1) Active participation of the parents is expected; their capacities and difficulties are looked at but they are expected to take on responsibility for their actions rather than rely on drugs.

(2) There is a special relationship of the patients to the hospital. The latter provides a physical structure in terms of the bricks and mortar of the building and its layout. This structure is looked after by patients and nurses, for example, in daily work groups which involve cleaning and maintenance. This allows patients to feel they are taking an active part in the life of the hospital.

(3) We provide sophisticated therapeutic structures. These include psychotherapeutic talking treatment undertaken in consulting rooms; nursing work which takes place in group and individual settings, mainly though not exclusively around activities; formal meetings for patients and staff; and supervision of the therapy and nursing. In addition, patients are involved in the life of the hospital community, which consists of their active participation in and their taking responsibility for such things as cooking teams, washingup rotas, and baby-sitting.

(4) In order to provide a framework for registering events in the Unit and for making sense of what takes place, we believe that effective transmission of information about patients is needed, as well as staff sharing of strains, and considerable support and supervision by the senior medical and other staff.

(5) The rights and needs of the child are kept to the forefront of all treatment, and this includes detailed understanding of the inner world of thoughts and feelings of the child, including understanding of their play. For this understanding to be skilled and effective, we need the input of the child psychotherapists attached to the Unit.

I should add that we see our role in the Families Unit not only to take on very difficult families for treatment but also to provide a resource for other workers in the field to use where appropriate. One of our main tasks is often to help other workers clarify their own positions with difficult families as well as offering an opinion on what we think is going on in the family. In addition, we feel we have the knowledge to help, through seminars and conferences, senior workers, administrators and others involved in the mental health field, clarify the complex issues raised by abusing families and other seriously disordered families.

\section{Summary of observations on physical abuse}

Although work on child abuse is widespread and the literature on it immense, there remains a number of important gaps in our knowledge of the nature of abuse and of the personality of the abuser, its long-term effects and the effectiveness of treatment programmes. Our own preliminary findings can be divided for convenience into general and specific features.

\section{(a) General features of chronic family breakdown}

In common with multi-problem families with no actual observed or reported physical abuse, this group displays general features of the breakdown of family life. In simple terms, these include the following characteristics: draining the financial and emotional resources and the patience of primary care teams and then specialist organisations; breakdown in ordinary, everyday activities so that basic events like organising meal and bed times cannot take place effectively; diffuse psychiatric symptoms such as chronic depression and anxiety in one or more parents; general symptoms in the affected children, 
including emotional or conduct disorders; and the inability of the parents to feel confident about keeping young children and babies in mind over vulnerable and critical periods, such as night-time or in situations of danger and risk, e.g. during boisterous physical activity. The last feature implies that families with these characteristics who may not immediately come to the notice of authorities for severe physical abuse may, however, be on the edge of abuse.

\section{(b) Specific features on the chronic abusing family}

We have repeatedly found that the parents do provide some caring for their children, but it is often only of a 'partial' kind. Other workers have described the frequent presence of 'role reversal', where the child is treated as if he or she were an adult, while the caretaker expects satisfaction of their own desires to be cared for. ${ }^{3}$ But we find that in addition the abusing parent, and often the partner where there is one, can only give 'divided' attention to the child who subsequently becomes the victim of abuse. This partial orientation reveals itself as the inability to fix on the needs of the child and to perceive his/her emotional pain. It is paralleled by the parents feeling enormously threatened by the possibility of experiencing in themselves feelings of vulnerability and dependency. Attempts to do so, such as acknowledging their dependency on a partner or a professional worker, are not infrequently accompanied by acute suicidal feelings. Their children are as a consequence subjected to repeated breakdowns in parental affection, which if untreated in the community may end in physical abuse. Frequently, when we have examined the timing of physical attacks on the children in consultations, we have discovered a recent episode which has evoked in the parent the threat or the possibility of experiencing dependent feelings.

The risk of this occurring is most clear in the Families Unit for in-patients around weekend separations from the hospital. Patients are expected to return to their homes for weekends, unless there is a crisis or something for them to work on in the hospital. Accounts given by the patients towards the end of the week often reveal them feeling threatened by having to experience dependent feelings towards the hospital. They may describe an 'unbearable' psychological pain and may also become a suicidal risk. Looking back over the pattern of attacks on children with these families, we have noticed how the expression of these feelings in the adult has been soon followed by the threat, and sometimes the reality, of some kind of attack on the child, though such attacks in the hospital are rarely severe enough to warrant legal action. Our hypothesis is that the existence of such feelings and severe attacks on their children are causally related. As a result of these observations, we have soon become more easily alerted to the risk of abuse.

Two factors in the history of these patients seem, in addition, of particular significance for understanding the nature of the disturbance. First of all, the parents may have had an experience of being parented as children, but there has been the absence of what one could call a 'fixed' relationship to the parents. A mother, or father, or even a parental substitute, may have been present, but the patient has experienced them as never having been 'central' to them, or never having provided central attention. As other workers have described, ${ }^{4}$ there is also usually a history of violent attacks on the child who subsequently becomes an abusing parent. Previous formulations have attempted to explain abuse by the fact that the abusing parent was abused as a child. However, this explanation does not take into account the fact that many parents who were treated violently as children do not become child abusers. In our opinion, it is the presence of the further factor of the lack of a fixed parental figure that tips the balance towards them becoming abusers.

But there may be a further necessary factor, which is a disturbed and difficult adolescence, which has predisposed to difficulties in coping with violence and depression. We are not yet certain of the role of adolescence in these cases, but many of the abusing parents left home early as a result of conflict with their parents, and then had had a stormy adolescence, with episodes of acute depression. Several parents had promiscuous sexual relations at this time, others attempted to deal with their adolescent problems by a premature first marriage which soon broke down. Some of these points are illustrated in the clinical examples. Our impression, which needs to be tested by research, is that there was often a threat of an adolescent breakdown, which was warded off by various environmental 'false' solutions of the kind just outlined.

There have been many descriptions of the immediate disturbance to the children as a result of suffering abuse. ${ }^{4}$ But few of these descriptions take detailed account of the child's own world of thoughts and feelings. Nor has there been adequate detailed study of the effects of treatment and what features are prognostic of a successful outcome. Our findings so far agree with other workers, ${ }^{5}$ in that the general effects of living in a chronically abusing family are multiple, including school failure, depression, sexualisation of behaviour and psychosomatic symptoms. It seems difficult to define more specific features. Our impression is that there is a tendency for these children, like their parents, to mask their emotions. The child appears to hold onto the idea of a 'marvellous' parent who needs protection. There may be a compulsion in the older child to provoke more parental abuse. The child may also have the greatest 
difficulty in seeing the parents as 'bad' in any way, thus making it in fact difficult for them to recover from the trauma of the abuse.

\section{Clinical examples}

Case 1 Mrs A and 6 year old 'Louise'

Mrs A, in her mid-30s, was admitted with Louise for possible rehabilitation following episodes of physical abuse by the step-father with Mrs A's complicity. The child was a Ward of Court, and I was given considerable responsibility for the case by the High Court. Mrs A had no memory of her father. She suspected that her mother was a prostitute, since there was a succession of men in the house at night, and she, and her sibs, had to look after themselves. On occasion they would have nothing to eat unless they managed to pawn something. She lived with an aunt when her mother disappeared when she was 6 . She hated the aunt who beat and starved her, while spoiling her own son. After a year, she was obliged to rejoin her mother and 'step-father' and lost contact with her sister of whom she was fond. She ran away to London when a young adolescent and soon married for 'food and security'. The marriage broke down and she abandoned the children of this liaison. Then began a series of embattled relationships with men who were heavy drinkers and violent, including the father of Louise. She saw her daughter as a reflection of herself, a lonely and damaged child, but found great difficulty providing both physical and emotional care for her. Louise herself presented as inhibited, unable to play and with inarticulate speech Her Wechsler Intelligence Scale for Children-Revised (WISC-R) score was 76

As a result of 15 months treatment, Mrs A was able to provide adequate and safe caring for her daughter. The major change in her seemed to be that she was more able to experience feelings of depression without either feeling hopelessly suicidal, or feeling criticised for being, in her own words, a 'bastard', or without trying to deny she had any problems at all. The fact that she was able to see me as an available authority figure who would not condemn her but would both stand up to her anger and hopefully understand her, seemed also of great importance. She was not able to blame 'authorities' outside the Unit but had to grapple with me more directly. Louise gradually came to life, was able to play more and express aggression without fear of retaliation. Her WISC-R is now 100 . Finally a major event occurred when Mrs A's boy-friend, a more suitable partner than previously, agreed to be admitted for the last part of the family's treatment, and he became a more benign and non-abusing father figure for Louise. Out-patient follow-up has continued. I continue to be given clinical authority by the High Court and I am supervising the social workers engaged with the family in the community. Our rough estimates have so far concluded that we have saved the taxpayer so far at least $£ 150,000$ in fostering, legal and medical costs by putting in an intense input of resources in the Unit.

Case $2 \mathrm{Mr}$ and Mrs B and baby Jean

The parents, in their early 20 s, and eight week old baby were admitted with the co-operation of the local social service department, for possible rehabilitation following episodes in which the father seriously bruised the baby, which was then put into care. The marital problem came quickly to the fore. Mrs B had little trust in her husband whom she would constantly denigrate. Mr B wished to be a 'perfect' father but was intensely jealous of the attention received by the baby. He wanted his wife's undivided attention. His own father had died when he was a young child of presenile dementia. He remembered him as forgetful, inactive and in need of care, while his mother was stretched by the demands made by the father. Mr B remembers being a difficult child to control and often left to his own devices. He left home as soon as he could, had many jobs and affairs, and became an excessive user of alcohol and cannabis, until his marriage.

Mrs B's own parents, from abroad, divorced when she was young. Her father was constantly unfaithful to her mother. The latter was described as depressed and unavailable to Mrs B. Baby Jean was named after a loved elder sister of Mrs B. Mrs B left school early and came to England. After a period of being lonely and depressed, then having an affair with an older man, she met her husband. Admission revealed severe mothering difficulties, in that Mrs B was disconnected from the baby. She wished she were a good mother but revealed little warmth to the baby or to her husband. She feared any show of dependency on either him or the staff. She stuck rigidly to an inappropriate feeding pattern and, when bathing Jean, left her in the cold. She was withdrawn and suspicious with little ability to focus her attention on the baby. When the original abuse had $\propto c-$ curred, she chose to leave her baby in hospital and return to the husband in order to be furious with him rather than stay and look after the baby. Rehabilitation was attempted slowly, but in spite of some progress, broke down after some months when the father gripped the baby too hard and bruised her. This coincided with the period when we, and the social service department, had agreed to proceed with rehabilitation. Contrary to expectation this produced a massive reaction of hostility to all the workers from the parents. Once again, Mrs B chose to leave the baby with the authorities.

\section{Case 3 Mrs D and 'Simon'}

Mrs D, in her early 20 s, was admitted some four years ago expecting her second child Simon. Her first child had been put into care for adoption as a result of severe physical abuse for which Mrs D and her husband were both responsible. It was feared that the same fate would happen to the next child. Following the entry of the first child into care, Mrs D attempted suicide by setting fire to the marital home. Pregnant again, Mrs D wished to end the marriage and was motivated for help with her relationship to the new baby, as she felt she had never been attached to her first child. Simon was born while she was an in-patient at the Cassel, and was immediately put on a place of safety order, followed by a full care order, with the full co-operation of the local social service department.

Initially, Mrs D gave the impression of being a somewhat wooden doll, with mechanical responses. She experienced considerable difficulty in having to participate in hospital events, and experienced staff interest in her as a persecution, particularly with regard to her handling of Simon. She revealed considerable difficulties in separating from him. Related to this was her inability at first to recognise and therefore deal with Simon's and her own dependency needs. We saw it as progress when she was able to express her irritation with Simon without excessive anxiety and without the fear of harming him. Mrs D described her own mother as an obsessional woman whose main concern was to keep the house tidy and who allowed little expression of feeling. 
Mrs D left the home at the age of 16 following a row with her mother and soon married the father of Simon.

Treatment focused both on Mrs D's mothering skills, helping her to promote Simon's development; on helping her face the reality of the abuse of her first child; and on fostering in her a different more positive attitude to the expression and understanding of emotions. Treatment was a success, and was particularly helped by a close working alliance with her social worker. On follow-up, some three years following discharge, Mrs D and Simon were well established and the care order on him had been removed.

\section{Discussion}

Judgements about suitability for treatment of these chronic abusing cases are difficult to make. If they were made on traditional grounds, such as motivation, willingness to co-operate, capacity to make a 'therapeutic alliance', and strength of personality, then it is likely that none of these families would be treatable. It is unclear what would be the consequences of not treating these families. It is likely that a significant number of children would come to more physical harm. It is probable that without intervention many children would suffer from long-term emotional disorder, and a proportion of these would end up, as they often do anyway, occupying places at special schools and becoming increasingly pushed onto the margins of society. In the absence of reliable long-term studies of this group of patients, it is not possible as yet to go beyond these impressions.

There is another pressing short-term problem, that of how to assess which families respond best to treatment, and what criteria there are for suggesting which families can be trusted to co-operate in treatment without subjecting their children to severe physical abuse. As yet we can only provide tentative answers to these questions. We believe that one important criterion for trustworthiness is the degree to which the patient can make specific emotional contact with the workers in a treatment setting. That is, trustworthiness is related to the degree of dependency that the patient can allow, as dependency implies the ability to make a specific attachment. If they are unable or unwilling to allow trust to develop, in spite of considerable and appropriate input, as in $\mathrm{Mr}$ and Mrs B's case, then it is likely that treatment will fail, although it must be said that one is often surprised at the ability of what appear to be hopelessly deprived parents to respond to the challenge of treatment when given a chance.

Making judgements about suitability for treatment is far from easy. At first glance, it seems to be a mainly intuitive activity and not easily amenable to testing. However a clinical judgement would be based, as it is in the Families Unit, on a number of observations obtained from medical, nursing and other staff. These include day to day accounts of the family's functioning, the presence or absence of inci- dents of minor physical harm which may indicate the potential for a more serious incident, what the patients say about their experience, and the amount of empathy they show to their children. Out-patient judgements would be based on similar, although less detailed, observations. Putting together all these observations into a coherent formulation which could become the basis of a treatment plan, is a skilled and often intuitive activity, as it is in the medical field proper. More rigorous definition of the concept of 'affective contact' and 'degree of dependency' could be envisaged, although as yet psychological tests of such higher personality functions seem crude compared to the clinician's own judgement of the patient in front of him in the consulting room, but nonetheless perhaps need assessing in this context. An additional point concerns the diagnostic treatment setting offered to these patients. To put the matter simply, if a one-to-one relationship of some kind, whether it be through the nursing, medical or other staff, is not offered to these patients, it is not likely that one can pick up the subtleties of their emotional life such that one can make a proper assessment of a capacity to engage with workers. It is our experience that there needs to be the offer of an individualised therapeutic relationship to the parents and if necessary to the child, for it provides a stable and 'integrating' experience for families who have not experienced consistent relationships.

Other workers ${ }^{3}$ have described factors associated with an incident of abuse, such as a crisis of some kind placing stress on the caretaker, lack of lifelines, and the perception of an 'unsatisfactory' child. Our work suggests that there is an underlying emotional disorder which provides the context for abuse. When testing out the safety of a family with regard to potential abuse, it seems to us essential to assess the emotional state of the individual parents as well as the state of the child at risk.

It is nearly 40 years since John Bowlby's work on the effects on children of maternal separation, which brought to focus the nature and extent of attachment problems. The families I have described in this paper suffer from a different kind of separation and attachment problem from what he described. These children seem to suffer from a repeated and cumulative series of 'mini', yet no less traumatic, separations throughout childhood, as a result of their parents' emotional disorder. It remains so far in the realm of speculation how far this disorder is a result of a basic deficit and how much is due to environmental failure.

\section{Acknowledgements}

My thanks to Steven Hirsch, Professor of Psychiatry, Charing Cross Hospital, for helpful discussions; and to the Families Unit staff for their unfailing enthusiasm and hard work. 


\section{References}

${ }^{1}$ Denford, J., Schachter, J., Temple, N. et al. (1983) Selection and outcome in in-patient psychotherapy. British Journal of Medical Psychology, 56, 225-243.

${ }^{2}$ Kennedy, R., Heymans, A. \& Tischler, L. (eds.) (1987) The Family as In-Patient. London: Free Association Books.

${ }^{3}$ STEELE, B. (1980) Psychodynamic factors in child abuse. In
The Battered Child (eds. C. H. Kempe and R. E. Helfer). Chicago: University of Chicago Press.

${ }^{4}$ MARTIN, H. P. (1980) The consequences of being abused and neglected: how the child fares. In The Battered Child (eds. C. H. Kempe and R. E. Helfer). Chicago: University of Chicago Press.

${ }^{5}$ Bentovim, A. (1987) The diagnosis of child sexual abuse. Bulletin of Royal College of Psychiatrists, 11, 295-299.

\title{
Consulting to a medium-term residential childrens' home
}

\section{A proposed model}

\author{
StePhen IsaACs, Consultant Child and Adolescent Psychiatrist Waltham Forest Child \\ and Family Consultation Service, London E17
}

There is a trend for new consultant posts in child psychiatry to be linked to Social Services Departments. I recently took up such a post, with four of my sessions funded by the local Social Services Department. Training of child psychiatrists for such consultative posts is variable, but I was fortunate to have trained as a senior registrar at the Tavistock Clinic, where one of the training options was a link with Camden Social Services through a placement at Camden Assessment Centre.

My training involved attending a weekly business meeting for the residential social workers from two of the medium-stay children's homes, followed by a staff meeting in one of these homes. A frequent experience was that the children would be discussed and the residential social workers would complain that there was no coherent plan for the work with the children following their placement. There was tension between residential and field social workers, with the residential workers frequently angry at the lack of availability of the field social workers responsible for the children's care, and at the way they experienced their treatment by field social workers as that of second-class citizens. I was particularly struck by the way that the residential workers passively accepted this role, and their complaints were largely directed in inappropriate places or in an ineffectual manner.

\section{Setting up a new consultation}

On beginning my post, I learnt that the staff at a medium-term children's home were hoping that I would consult to their staff group. This home can accommodate up to 12 children, mainly adolescents, for periods up to two years. My previous experience in consultation work owes much to the ideas of Caplan $^{1}$, who stresses the importance of making personal contact with the authority figures of the consultee institution. I therefore began by arranging to meet the principal child care officers, in order to explore what was requested of me and what ideas they might have.

I subsequently visited the officer in charge of this home. I was informed that the staff wished to hold weekly case discussion meetings, each on an individual child in their care, and that all the day staff would be present for these meetings. I then visited a shortstay children's home in the District and learnt from the officer-in-charge that all admissions are followed by an initial planning meeting within 48 hours of the child's entering the home, which the area team field social worker must attend.

\section{The format}

A further suggestion of Caplan ${ }^{1}$ which I have found essential is that a consultant should follow the 